\title{
Association of miR-196a2 and miR-149 single-nucleotide polymorphisms with atherosclerotic ischemic stroke susceptibility
}

\author{
Dina Mahmoud ${ }^{1 *}$ D, Ola El-Sisi ${ }^{1}$, Marwa Sheta ${ }^{1}$, Sandra Ahmed ${ }^{2}$, Mona Fathy ${ }^{1}$, Kareeman Gomaa ${ }^{1}$ and \\ Tarek Ramzy ${ }^{1}$
}

\begin{abstract}
Background: Beside common risk factors for stroke such as diabetes and hypertension, single-nucleotide variants occurring within micro RNA genes have been identified as susceptibility loci for ischemic stroke risk.

Objectives: Investigate the possible association of two variants in pre miRNA sequences, rs11614913 within miR196a2 C > T and rs2292832 within miR-149 T > C, with ischemic stroke.

Subjects and methods: One hundred ischemic stroke patients and 100 age and sex-matched controls having $>1$ risk factor for atherosclerosis were enrolled in a case-control study. Degree of atherosclerosis was assessed using ultrasonography. Micro RNA variants were assessed by real-time PCR TaqMan probe assay.

Results: The TT genotype and T allele frequencies of miR-196a2 C > T were protective against ischemic stroke (OR $0.168, P$ 0.001; OR 0.482, $P<0.001$ respectively). While among miR-149 T $>C$ variants, CC genotype was associated with increased risk by threefold (OR 3.061, $P$ 0.005) and $C$ allele was associated with about 1.9 fold risk of stroke (OR 1.909, P 0.002). Haplotypes analysis revealed miR-196a2T/-149 T allele combination was significantly lower among stroke patients than the controls $(P<0.001)$ with a protective effect (OR 0.196, 95\% Cl 0.083-0.466).

Conclusion: A decrease in the incidence of ischemic stroke is associated with miR-196a2 $\Pi$ genotype and T allele and increases in the likelihood risk of ischemic stroke are associated with CC genotype and C allele within miR-149, and the two miRNAs under study are closely associated with vascular damage responses.
\end{abstract}

Keywords: Ischemic stroke, Micro RNAs, miR-149, miR-196a2

\section{Introduction}

Stroke is defined as a focal neurological impairment resulting from disruption of cerebral blood supply. It is one of the three most common causes of death and one of the leading causes of serious, long-term disability [1]. At least $80 \%$ of stroke is ischemic, resulting from an obstruction of cerebral blood flow by atherosclerotic plaque or embolus, whereas

\footnotetext{
* Correspondence: dina.mahmoud@kasralainy.edu.eg

${ }^{1}$ Clinical and Chemical Pathology Department, Faculty of Medicine, Cairo University, Cairo, Egypt

Full list of author information is available at the end of the article
}

$15-20 \%$ is due to intracerebral hemorrhage [2]. Ischemic stroke itself has a number of subtypes with the most common being large-vessel atherosclerotic stroke, small-vessel disease, and cardio embolism [3].

Besides the conventional risk factors such as diabetes mellitus (DM), hypertension, and smoking, singlenucleotide variants (SNV) have been identified in genome-wide association studies as susceptibility loci for ischemic stroke risk. Part of these variants occurs within micro RNA genes [4].

\section{Springer Open}

(c) The Author(s). 2020 Open Access This article is licensed under a Creative Commons Attribution 4.0 International License, which permits use, sharing, adaptation, distribution and reproduction in any medium or format, as long as you give appropriate credit to the original author(s) and the source, provide a link to the Creative Commons licence, and indicate if changes were made. The images or other third party material in this article are included in the article's Creative Commons licence, unless indicated otherwise in a credit line to the material. If material is not included in the article's Creative Commons licence and your intended use is not permitted by statutory regulation or exceeds the permitted use, you will need to obtain permission directly from the copyright holder. To view a copy of this licence, visit http://creativecommons.org/licenses/by/4.0/. 
Micro RNAs (miRNAs) are a class of small, noncoding ribonucleic acids (RNAs) that pair with 3 '-untranslated regions (UTR) in messenger RNAs (mRNAs) to downregulate their expression. The discovery of miRNAs as key regulators of gene function introduced the mechanism of gene regulation [5].

MiR196a2 is a part of miRNA 196 precursor family which is located in the regions of homeobox (HOX) clusters within the human genome. HOX genes encode homeodomain-containing transcription factors that are essential for embryonic development [6].

Annexin A1 expression was mediated by miR-196a2 [7]. Annexin A1 is known to be an important endogenous anti-inflammatory mediator and a negative regulator of the expression of IL- 6 and TNF $\alpha$ by macrophages. It was identified in leucocytes as a glucocorticoid-inducible protein that inhibits phospholipase A2 and prevents the formation of pro-inflammatory eicosanoids. It can also repress the expression and activation of inflammatory enzymes, such as inducible cyclooxygenase 2 (COX2) and inducible nitric oxide synthase (NOS) [8].

Studies found that Annexin A1 protein expression in human asymptomatic plaques will stabilize carotid plaques through an anti-inflammatory mechanism. Thus, enhancement of its expression was probably protective against a series of inflammatory events to stabilize the plaques and prevent plaque rupture [9]. Annexin A1 3' UTR is a potential target for miR-196a 2 which account for the mRNA degradation and consequent reduction in translation to Annexin A1 protein. Pre-miR196a overexpression consistently led to a significant downregulation of Annexin A1 mRNA level and concomitant reduction in protein level [10].

SNV in pre-miRNA sequences, miR-196a2 C $>\mathrm{T}$ (rs11614913) may have influence on mature form expression [11].

MiRNA-149 can affect the metabolic pathway of methylenetetrahydrofolate reductase (MTHFR) which in consequences affects the susceptibility of ischemic stroke. Studies have found that the variant of miR-149 T > C (rs2292832) could affect the function and level of its mature form, which therefore affects MTHFR regulation [12]. MTHFR catalyzes the reduction of 5,10-methyltetrahydrofolate (5,10-MTHF) to 5-methyltetrahydrofolate (5MTHF) for methylation of homocysteine to methionine, which is involved in DNA methylation and DNA synthesis/mismatch repair [13].

Abnormal MTHFR function is related to low folate status in plasma/red blood cells and cause serious health problems as increased risks for coronary, cerebral atherosclerosis, and venous thrombosis, possibly due to an effect of elevated homocysteine on the vascular endothelium [10].

The purpose of this study was to investigate the possible association of two variants in pre miRNA sequences, rs11614913 within miR-196a $2 \mathrm{C}>\mathrm{T}$ and rs2292832 within miR-149 $\mathrm{T}>\mathrm{C}$, with atherosclerotic ischemic stroke.

\section{Subjects and methods}

This study enrolled 200 subjects divided into 2 groups. Group 1 included 100 patients (64 males and $36 \mathrm{fe}$ males) presented with atherosclerotic ischemic stroke to Stroke Unit, Kasr El Aini Hospital, Cairo University, Egypt. Group 2 included 100 age and sex-matched individuals (61 males and 39 females) have more than one risk factor for atherosclerotic ischemic stroke with no evidence of cerebrovascular disease, ischemic heart diseases, or peripheral arterial diseases, recruited from Kasr El Aini outpatient clinic. The enrolment period extended from January 2017 to April 2019.

Hypertension was defined as systolic pressure $>140$ $\mathrm{mm} \mathrm{Hg}$ and diastolic pressure $>90 \mathrm{~mm} \mathrm{Hg}$ on $>1$ occasion, included patients currently taking hypertensive medications. Diabetes mellitus was defined as a fasting plasma glucose level $>126 \mathrm{mg} / \mathrm{dL}$, included patients taking diabetic medications. Smoking refers to patients who currently smoke. Hyperlipidemia was defined as serum total cholesterol level $\geq 240 \mathrm{mg} / \mathrm{d}$ or an antihyperlipidemic agent treatment history.

Inclusion criteria: (1) Age ranging from 20 to 80 years. (2) Adult patients with atherosclerotic ischemic stroke whether males or females. Exclusion criteria: (1) Age less than 20 years. (2) Patients with cerebral hemorrhage, transient ischemic attack, cerebral embolism, cerebral trauma, cerebrovascular malformations. (3) Non-Egyptians.

All participants were subjected to full history: especially for risk factors for ischemic heart disease, peripheral artery disease, or cerebrovascular events as transient ischemic attack (TIA).

Clinical assessment: Eligible patients were defined as those who were diagnosed as acute ischemic stroke according to neurological examination and radiological imaging, including a sudden onset of focal neurological deficit for more than $24 \mathrm{~h}$ with corresponding infarction on brain imaging (computed tomography and magnetic resonance imaging). Patients were also subjected to the National Institutes of Health Stroke Scale (NIHSS) [14] scale on admission to quantifying the impairment and degree of severity caused by stroke. NIHSS is composed of 11 elements: level of consciousness, best gaze, visual, facial palsy, motor arm, motor leg, limb ataxia, sensory, best language, dysarthria, extinction, and inattention. For each item, a score of 0 typically indicates normal function, while a higher score indicates the level of impairment. These 11 components are summed then the score was correlated with stroke severity as follow: $0=$ no stroke symptoms, $1-4=$ minor stroke, $5-15=$ 
moderate stroke, $16-20=$ moderate to severe stroke, 21 $42=$ severe stroke.

Grading of large artery atherosclerosis ultrasound of the extra-cranial carotid system and intra-cranial vasculature was done to assess large vessel atherosclerosis of the cerebrovascular circulation. The machine used was the Philips iU22 (Philips iU22-series made in the USA) with a linear high frequency probe $(5-12 \mathrm{MHz})$ for extracranial carotid system and sector low frequency probe (1-5 MHz) for transcranial examination.

Extra-cranial stenosis: Using the Von Reutern and colleagues criteria [15], low grade stenosis was $0-40 \%$, moderate stenosis was $50-60 \%$, and severe stenosis was $\geq$ $70 \%$.

Intracranial stenosis: Based on a large multicenter study [16], we considered moderate stenosis of intracranial vessels if it was from $50-70 \%$ and severe if the stenosis was $>70 \%$. The stenosis was based on mean flow velocity of large intracranial arteries. Presence of turbulence (in absence of anemia or hyperdynamic circulation) with no major hemodynamic affection was considered the mildest degree of stenosis.

Laboratory investigations: Random blood sugar and lipid profile were recruited from patients' files.

Sample collection and DNA Extraction: Two milliliters of venous blood was withdrawn from all subjects and collected in a sterile vacutainer EDTA, for DNA extraction. GeneJET Genomic Purification Mini Kit (\#K0781), Thermo Fisher, Life Technologies (Carlsbad, California 92008) was used for DNA extraction. Real-time PCR TaqMan probes allelic discrimination assays for Genotyping assay C > T variant of of miR-196a2 (rs11614913) and T > C variant of miR-149 (rs2292832) were determined using Custom TaqMan ${ }^{\circ}$ SNP Genotyping Assays from Applied Biosystems and consequent analysis was performed on DNA-Technology DTlite Real-Time PCR Thermal Cycler (LLC Varshavskoe shosse, Moscow, Russia).

The context sequence for rs 11614913 of miR-196a 2 was Forward 5' -TTTTGAACTCGGCAACAAGAAACTG$3^{\prime}[\mathbf{C} / \mathbf{T}]$

Reverse 5'-CTGAGTTACATCAGTCGGTTTTCGT3 '. Variant: $\mathrm{C} / \mathrm{T}$, transition substitution.

The context sequence for rs2292832 of miR-149 was

Forward 5'-GGGACGGGGGCTGTGCTGGGGCAGC3' $[\mathrm{T} / \mathrm{C}]$

Reverse 5'-GGAACAACGCAGGTCGCCGGGCCGG3' Variant: $\mathrm{T} / \mathrm{C}$, transition substitution.

All reactions were performed in a total volume of $20 \mu \mathrm{L}$ containing $10 \mu \mathrm{L}$ of master mix, $0.5 \mu \mathrm{L}$ of SNPreadymade assay, 1-5 $\mu \mathrm{L}$ purified DNA solution according to DNA concentration, to be completed to $20 \mu \mathrm{L}$ of nuclease-free water. (c) Allelic Discrimination Plate Read and Analysis: After PCR amplification, an endpoint plate read was performed using The DTlite master Software to plot fluorescence values based on the signals from each well which indicated allele's type in sample. Automatic allele calls were made then converted to genotypes.

\section{Statistical analysis}

Data were entered and analyzed using the IBM-SPSS software (IBM Corp. Released 2017.IBM SPSS Statistics for Windows, Version 25.0. Armonk, NY: IBM Corp.). Data was summarized using mean and standard deviation for quantitative variables, while frequencies (number of cases) and relative frequencies (percentages) for categorical variables. Comparisons between quantitative variables were done using unpaired $T$ test. For comparing categorical data, chi-square test was performed. Exact test was used instead when the expected frequency is less than 5 . Odds ratio (OR) with $95 \%$ confidence intervals was calculated [17]. $P$ values less than 0.05 were considered as statistically significant.

\section{Results}

The study included 100 ischemic stroke patients with a mean age of $53 \pm 10$ years old and 100 individuals (mean age of $50 \pm 8$ years old) with no evidence of atherosclerotic events as controls. Demographic data associated comorbidities and risk factors of studied groups are summarized in Table 1.

Table 1 Demographic data, associated co-morbidities, and risk factors of studied groups

\begin{tabular}{llll}
\hline & $\begin{array}{l}\text { Group 1 cases } \\
(\boldsymbol{n}=100)\end{array}$ & $\begin{array}{l}\text { Group2 controls } \\
(\boldsymbol{n}=100)\end{array}$ & $\boldsymbol{P}$ value \\
\hline $\begin{array}{l}\text { Age (years) mean } \pm \text { SD } \\
\text { Sex }\end{array}$ & $53 \pm 10$ & $50 \pm 8$ & 0.070 \\
$\quad$ Male, $n(\%)$ & $64(64)$ & $61(61)$ & 0.661 \\
$\quad$ Female & $36(36)$ & $39(39)$ & \\
DM, $n(\%)$ & $47(47)$ & $59(59)$ & 0.089 \\
Hypertension, $n(\%)$ & $59(59)$ & $61(61)$ & 0.773 \\
Smoker, $n(\%)$ & $40(40)$ & $46(46)$ & 0.391 \\
Hyperlipidemia, $n$ (\%) & $28(28)$ & $39(39)$ & 0.099 \\
NIHSS score ${ }^{*} n$ (\%) & & & \\
Mild & $50(50)$ & & \\
Moderate & $44(44)$ & & \\
Severe & $6(6)$ & & \\
Atherosclerotic severity (duplex) & & \\
Normal & $22(22)$ & & \\
Mild & $44(44)$ & & \\
Moderate & $18(18)$ & & \\
Severe & $16(16)$ & & \\
\hline
\end{tabular}

*NIHSS score, National Institutes of Health Stroke Scale 
Table 2 Genetic characteristics of the studied groups

\begin{tabular}{|c|c|c|c|c|c|c|}
\hline & & Group1 cases $(\boldsymbol{n}=100)$ & Group2 controls $(\boldsymbol{n}=100)$ & $\boldsymbol{P}$ value & Odds ratio & $95 \% \mathrm{Cl}$ \\
\hline \multirow[t]{3}{*}{ Genotyping of miR $196 a 2 \mathrm{C}>\mathrm{T}, n(\%)$} & $\mathrm{TT}$ & $5(5)$ & $21(21)$ & 0.001 & 0.168 & $(0.058-0.484)$ \\
\hline & $\mathrm{CT}$ & $41(41)$ & $41(41)$ & 0.251 & 0.704 & $(0.386-1.282)$ \\
\hline & $\mathrm{CC}$ & $54(54)$ & $38(38)$ & Reference & Reference & Reference \\
\hline \multirow[t]{2}{*}{ Allele frequency of miR $196 \mathrm{a} 2 \mathrm{C}>\mathrm{T}, n(\%)$} & $\mathbf{T}$ & $51(25.5)$ & $83(41.5)$ & 0.001 & 0.482 & $(0.316-0.738)$ \\
\hline & $\mathrm{C}$ & $149(74.5)$ & $117(58.5)$ & Reference & Reference & Reference \\
\hline \multirow[t]{3}{*}{ Genotyping of miR $149 \mathrm{~T}>\mathrm{C}, n(\%)$} & $\mathrm{CC}$ & $57(57)$ & $45(45)$ & 0.005 & 3.061 & $(1.406-6.665)$ \\
\hline & $\mathrm{CT}$ & $31(31)$ & $26(26)$ & 0.015 & 2.881 & $(1.230-6.748)$ \\
\hline & $\mathrm{TT}$ & $12(12)$ & $29(29)$ & Reference & Reference & Reference \\
\hline \multirow[t]{2}{*}{ Allele frequency of miR $149 \mathrm{~T}>\mathrm{C}, n(\%)$} & $\mathrm{C}$ & $145(72.5)$ & $116(58)$ & 0.002 & 1.909 & $(1.256-2.901)$ \\
\hline & $T$ & $55(27.5)$ & $84(42)$ & Reference & Reference & Reference \\
\hline
\end{tabular}

Regarding miR196a2C > T variant analysis: TT genotype distribution was significantly lower among cases than controls $(P=0.001)$. Using the $C C$ genotype as a reference, TT genotype of the miR-196a 2 variant was associated with a decrease risk of ischemic stroke in the studied sample (OR $=0.168,95 \%$ CI: 0.058-0.484).

As regard allele frequency, "C" allele was the commonest allele in the studied groups observed in $74.5 \%$ and $58.5 \%$ of cases and controls respectively, while " $\mathrm{T}$ " allele represents the minor allele frequency representing 25.5\% and $41.5 \%$ of cases and controls respectively, which was statistically significant (OR 0.482, CI 0.316-0.738; $P=$ 0.001) (Table 2).

Considering the dominant and recessive role of minor frequent alleles " $\mathrm{T}$," it was associated with decrease risk of ischemic stroke $(\mathrm{TT}+\mathrm{CT}$ versus CC: $\mathrm{OR}=0.522$, 95\% CI: 0.297-0.917, P 0.024; TT versus CC + CT: OR = 0.198, 95\% CI: 0.071-0.549, $P$ 0.002) (Table 2).

Regarding $149 \mathrm{~T}>\mathrm{C}$ variant analysis: The distribution of miR-149 $\mathrm{T}>\mathrm{C}$ genotype variant was significantly different between the two groups. Using the TT genotype as a reference, CT had an OR of 2.881 (95\% CI: 1.230-
6.748, $P$ 0.015). The OR for CC was 3.061 (95\% CI: $1.406-6.665, P$ 0.005). The " $C$ " allele was the most abundant allele, while " $\mathrm{T}$ " allele represented minor allele frequent. "C" allele was associated with increased risk of ischemic stroke in the studied sample (OR 1.909, 95\% CI 1.256-2.901; $P=0.002$ ) (Table 2).

Among cases, there were no significant associations between miR196a2 or miR-149 $\mathrm{T}>\mathrm{C}$ genotype frequencies with age of patients, nor severity of impairment quantified by NIHSS score and duplex findings $(P>0.05)$ (Table 3 ).

Haplotype analysis of both miR-149 T $>\mathrm{C}$ and miR196a2C > T alleles: We constructed possible allele combinations of miR-196a2 and miR-149. MiR196a2T/-149 T allele combination frequencies were significantly different between the two studied groups $(P<0.001)$ with protective effect (OR $0.196,95 \% \mathrm{CI}$ 0.083-0.466) (Table 4).

\section{Discussion}

Most cases of stroke represent a multifactorial disorder or complex trait for which classical patterns of inheritance cannot be demonstrated. The major conventional

Table 3 Relation between genotypes, age and severity of impairment (NIHSS score and duplex)

\begin{tabular}{|c|c|c|c|c|c|c|c|c|c|}
\hline & & \multicolumn{3}{|c|}{ miR-196a2 C > T } & \multirow{3}{*}{$\begin{array}{l}\boldsymbol{P} \\
\text { value }\end{array}$} & \multicolumn{3}{|c|}{ miR-149T >C } & \multirow{3}{*}{$\begin{array}{l}P \\
\text { value }\end{array}$} \\
\hline & & $\pi$ & $C T$ & $\mathrm{CC}$ & & \multirow{2}{*}{$\begin{array}{l}\text { CC } \\
\boldsymbol{n}=57\end{array}$} & \multirow{2}{*}{$\begin{array}{l}\text { CT } \\
\boldsymbol{n}=31\end{array}$} & $\pi$ & \\
\hline & & $\boldsymbol{n}=5$ & $\boldsymbol{n}=41$ & $\boldsymbol{n}=54$ & & & & $\boldsymbol{n}=12$ & \\
\hline \multirow[t]{2}{*}{ Age (years), $n(\%)$} & $<40, n=11$ & $0(0)$ & $7(64)$ & $4(36)$ & 0.999 & $3(27)$ & $7(64)$ & $1(9)$ & 0.682 \\
\hline & $>40, n=89$ & $5(6)$ & $34(38)$ & $50(56)$ & & $54(61)$ & $24(27)$ & $11(12)$ & \\
\hline \multirow[t]{3}{*}{ NIHSS, $n(\%)$} & Mild, $n=50$ & $2(40)$ & $23(56)$ & $25(46)$ & 0.122 & $31(54)$ & $15(48)$ & $4(33)$ & 0.580 \\
\hline & Moderate, $n=44$ & $2(40)$ & $14(34)$ & $28(52)$ & & $22(39)$ & $15(48)$ & $7(58)$ & \\
\hline & Severe, $n=6$ & $1(20)$ & $4(10)$ & $1(2)$ & & $4(7)$ & $1(4)$ & $1(9)$ & \\
\hline \multirow[t]{4}{*}{ Atherosclerotic severity (duplex), $n(\%)$} & Normal, $n=22$ & $0(0)$ & $13(32)$ & $9(17)$ & 0.423 & $10(18)$ & $9(29)$ & $3(25)$ & 0.479 \\
\hline & Mild, $n=44$ & $4(80)$ & $15(37)$ & $25(46)$ & & $27(47)$ & $11(35)$ & $6(50)$ & \\
\hline & Moderate, $n=18$ & $1(20)$ & $7(17)$ & $10(18.5)$ & & $8(14)$ & $8(26)$ & $2(17)$ & \\
\hline & Severe, $n=16$ & $0(0)$ & $6(14)$ & $10(18.5)$ & & $12(21)$ & $3(10)$ & $1(8)$ & \\
\hline
\end{tabular}


Table 4 Haplotypes analysis of miR-196a2T > C and miR-149 T > C alleles

\begin{tabular}{lllllll}
\hline & & $\begin{array}{l}\text { Group1 cases } \\
(\boldsymbol{n}=100)\end{array}$ & $\begin{array}{l}\text { Group 2 controls } \\
(\boldsymbol{n}=100)\end{array}$ & $\begin{array}{l}\boldsymbol{P} \\
\text { value }\end{array}$ & $\begin{array}{l}\text { Odds } \\
\text { ratio }\end{array}$ & $\begin{array}{c}95 \% \mathrm{Cl} \\
\text { Haplotypes, }\end{array}$ \\
$\begin{array}{l}n(\%) \\
\text { miR-196a2C }>\end{array}$ & CC & $102(51)$ & $72(36)$ & 0.240 & 1.356 & $0.816-2.254$ \\
$\begin{array}{l}\text { T and miR-149 T } \\
>\text { C alleles }\end{array}$ & TC & $43(21.5)$ & $44(22)$ & 0.824 & 0.936 & $0.521-1.682$ \\
& TT & $8(4)$ & $39(19.5)$ & $<0.001$ & 0.196 & $0.083-0.466$ \\
\hline
\end{tabular}

risk factors as high blood pressure, DM, hyperlipidemia, and smoking account for a significant part of stroke risk, but much risk remains unexplained [4].

MiR-196a2 and miR-149 and miRNAs can affect vascular damage responses through regulation of Annexin A1 and MTHFR respectively. These miRNA targets are related to thrombosis or inflammation pathways in the circulation system. Few data are available regarding the possible role of miRNA variants on stroke pathogenesis [18]. Therefore, the aim of this study was to investigate the possible association of miR-149 and miR-196a2 gene variants with the risk of ischemic stroke and its outcome.

The results of the current study demonstrated that within miR-196a2 (rs11614913) TT genotype and T allele were protective against ischemic stroke (OR 0.168, $P$ 0.001 ; OR $0.482, P<0.001$ respectively). TT genotype frequency was significantly lower in stroke patients than the controls $(P 0.001)$. C allele was the major allele frequency in the studied population and this was consistent with 1000 Genomes and Genome Aggregation Database which identified $\mathrm{C}$ allele as more abundant allele in global and European population [19].

In accordance with our results Jeon and colleagues [20] and Park and colleagues [21] found that miR$196 \mathrm{a} 2 \mathrm{~T}$ allele has protective role in stroke pathogenesis and $C$ allele increases miRNA-196a expression levels with subsequent downregulation of Annexin A1, which is an important endogenous anti-inflammatory mediator, confers protection in both myocardial, and brain models of ischemia and reperfusion injury.

These speculations support our finding about the protective effect of the $\mathrm{T}$ allele of miR-196a2 through preservation of Annexin A1 protein expression.

However, several studies [22-24] negated an association between the miR-196a2 rs11614913 and ischemic stroke risk. This discrepancy was not a surprise when we found different genetic background between our studied population and Asian population, that the minor frequency allele $(\mathrm{T})$ in our studied population was the major allele frequency in the Asian population.

The result of current study clarified that miR-149 T > $\mathrm{C}$ variant was associated with increased risk of ischemic stroke in studied population ( $P$ 0.005). The presence of the $\mathrm{C}$ allele was associated with about 1.9 fold risk of stroke (OR 1.909, P 0.002), while the presence of CC genotype was associated with increased risk by threefold (OR 3.061, P 0.005). The C allele of miR 149 variant was the major frequent allele in our studied groups and this is consistent with 1000 Genomes and Genome Aggregation Database which identified $C$ allele as the more frequent allele in global and European population [25].

In a harmony, Du and colleagues [26] and Zou and colleagues [24] found that miR-149 $\mathrm{T}>\mathrm{C}$ variant was significantly associated with the risk of a stroke under allelic model $\mathrm{C}$ vs $\mathrm{T}(\mathrm{OR}, 1.14 ; P$ 0.03) and homologous model CC vs TT (OR, 1.36; $P$ 0.02). Whereas Xiao and colleague [27] indicated that the TT genotype and T allele of miR-149 (rs2292832) are associated with significantly lower ischemic stroke risk.

The mir-149 $\mathrm{T}>\mathrm{C}(\mathrm{rs} 2292832)$ variant affects the maturation process and consequently regulation of the miR-149 expression level. Studies reported that T allele may disrupt the maturation process compared with $\mathrm{C}$ allele and, consequently, decrease miR-149 expression with subsequently upregulation of MTHFR expression as one of its target gene with subsequent reduction in homocysteine level accumulation [28].

In contrast Bastami and colleagues [11] and Luo and colleagues [29] reported that miR-149 was not associated with cardio-cerebrovascular diseases risk. The distributional difference of rs2292832 genotype frequencies within mir-149 among people of various races and ethnicities may be the cause of contradictory where the frequencies of $\mathrm{C}$ allele of rs2292832 were much lower in Asian populations than those in our studied population as seen in dbSNP data base [25].

In conclusion, the 2 miRNAs we studied are closely associated with vascular damage responses. We detected the presence of miR-196a2 TT genotype and T allele is associated with decrease incidence of ischemic stroke. While the presence of CC genotype and $C$ allele within miR-149 is associated with increased risk of ischemic stroke in studied population. Haplotypes analysis revealed miR-196a2T/-149 T allele combination were significantly lower among stroke patients than the controls $(P<0.001)$ with a protective effect (OR 0.196, 95\% CI 0.083-0.466).

Performing the study on a larger scale of patients with concomitant measuring of homocysteine and TNF $\alpha$ levels is needed to gain greater insight into the biological 


\section{function of miR-196a $2 \mathrm{C}>\mathrm{T}$ and miR-149 $\mathrm{C}>\mathrm{T}$ variant on ischemic stroke pathogenesis.}

\section{Acknowledgements}

We would like to thank Stroke Unit team, Kasr El Aini Hospital, Cairo University, Egypt for their help during progression of this work.

\section{Authors' contributions}

Dr. MD: Idea, data collection, statistical analysis, writing, revision, and approval of final draft. Dr. SO: Idea of the research, writing, and approval of the final draft. Dr. SM: Idea, data organization, statistical analysis, and approval of the final draft. Dr. AS: Conception of the idea, selection of cases from neurology department, clinical diagnosis, performance of ultrasound and grading of atherosclerosis, writing, and approval of final draft. Dr. FM: Idea of the research, writing, and approval of the final draft. Dr. GK: Idea, data collection, statistical analysis, and approval of final draft. Dr. RT: Idea of the research, writing, and approval of the final draft. The author(s) read and approved the final manuscript.

\section{Funding}

This work was funded by Faculty of Medicine, Cairo University by purchasing molecular work kits.

\section{Availability of data and materials}

The datasets used and/or analyzed during the current study are available from the corresponding author on reasonable request.

\section{Ethics approval and consent to participate}

The study was approved by Cairo University research committee by Professor Fatama Almogy, the committee's date July 11, 2017. The research was conducted ethically in accordance with the World Medical Association Declaration of Helsinki. All participants or next of kin signed an informed consent before enrolment.

\section{Consent for publication}

Not applicable

\section{Competing interests}

The authors have no conflicts of interest to declare.

\section{Author details}

${ }^{1}$ Clinical and Chemical Pathology Department, Faculty of Medicine, Cairo University, Cairo, Egypt. ${ }^{2}$ Neurology Department, Faculty of Medicine, Cairo University, Cairo, Egypt.

Received: 7 July 2020 Accepted: 5 August 2020

Published online: 20 August 2020

\section{References}

1. Vijayan M, Reddy PH. Stroke, vascular dementia, and Alzheimer's disease: molecular links. J Alzheimers Dis. 2016:54(2):427-43.

2. Chandra A, Stone CR, Du X, Li WA, Huber M, Bremer R, et al. The cerebral circulation and cerebrovascular disease III: stroke. Brain Circ. 2017:3(2):66.

3. Harris S, Sungkar S, Rasyid A, Kurniawa M, Mesiano T, Hidayat R. TOAST Subtypes of ischemic stroke and its risk factors: a hospital-based study at Cipto Mangunkusumo Hospital, Indonesia. Stroke Res Treat. 2018;9589831:6.

4. Boehme AK, Esenwa C, Elkind MS. Stroke risk factors: genetics and prevention. Circ Res. 2017;120(3):472-95.

5. Chen K, Rajewsky N. The evolution of gene regulation by transcription factors and microRNAs. Nat Rev Genet. 2007;8(2):93.

6. Fantini S, Salsi V, Zappavigna V. HOX cluster-embedded micro-RNAs and cancer. Biochimica et Biophysica acta. Rev Cancer. 2018;1869(2):230-47. https://doi.org/10.1016/j.bbcan.2018.03.002.

7. Luthra R, Singh RR, Luthra MG, Li YX, Hannah C, Romans AM, et al. MicroRNA-196a targets annexin A1: a microRNA-mediated mechanism of annexin A1 downregulation in cancers. Oncogene. 2008;27(52):6667-78.

8. Zhao B, Wang J, Liu L, Li X, Liu S, Xia Q, et al. Annexin A1 translocates to nucleus and promotes the expression of pro-inflammatory cytokines in a PKC-dependent manner after OGD/R. Sci Rep. 2016;6(1):1-3.
9. Cheuk BL, Cheng SW. Annexin A1 expression in atherosclerotic carotid plaques and its relationship with plaque characteristics. Eur J Vasc Endovasc Surg. 2011;41(3):364-71.

10. Škovierová H, Vidomanová E, Mahmood S, Sopková J, Drgová A, Červeňová $\mathrm{T}$, et al. The molecular and cellular effect of homocysteine metabolism imbalance on human health. Int J Mol Sci. 2016;17(10):1733.

11. Bastami M, Choupani J, Saadatian Z, Zununi Vahed S, Mansoori Y, et al. miRNA polymorphisms and risk of cardio-cerebrovascular diseases: a systematic review and meta-analysis. Int J Mol Sci. 2019;20(2):293.

12. Zanger UM, Klein K, Kugler N, Petrikat T, Ryu CS. Epigenetics and microRNAs in pharmacogenetics. Adv Pharmacol. 2018;83:33-64 Academic Press.

13. Li C, Ni J, Liu YX, Wang H, Liang ZQ, Wang X. Response of MiRNA-22-3p and MiRNA-149-5p to folate deficiency and the differential regulation of MTHFR expression in normal and cancerous human hepatocytes. PLoS One. 2017; 12(1):e0168049.

14. Edwardson MA, Dromerick AW, Kasner SK. Ischemic stroke prognosis in adults. Up To date. com/content/ischemic-stroke-pronosis-in-adults; 2015. p. 28.

15. Von Reutern GM, Goertler MW, Bornstein NM, Del Sette M, Evans DH, Hetzel A, et al. Grading carotid stenosis using ultrasonic methods. Stroke. 2012; 43(3):916-21.

16. Zhao L, Barlinn K, Sharma VK, Tsivgoulis G, Cava LF, Vasdekis SN, et al Velocity criteria for intracranial stenosis revisited: an international multicenter study of transcranial Doppler and digital subtraction angiography. Stroke. 2011:42(12):3429-34.

17. Chan YH. Biostatistics 202: logistic regression analysis. Singap Med J. 2004 45(4):149-53.

18. Darabi H, Salmaninejad A, Jaripour ME, Azarpazhooh MR, Mojarrad M, SadrNabavi A. Association of the genetic polymorphisms in immunoinflammatory microRNAs with risk of ischemic stroke and subtypes in an Iranian population. J Cell Physiol. 2019;234(4):3874-86.

19. Ncbi.nlm.nih.gov. (2019) rs11614913 Ref SNP Report-dbSNP-NCBI. [Online] Available at: http://www.ncbi.nlm.nih.gov/snp/rs11614913 [Accessed on 1Aug.2019].

20. Jeon YJ, Kim OJ, Kim SY, Oh SH, Oh D, Kim OJ, et al. Association of the miR146a, miR-149, miR-196a2, and miR-499 polymorphisms with ischemic stroke and silent brain infarction risk. Arterioscler Thromb Vasc Biol. 2013; 33(2):420-30.

21. Park YS, Jeon YJ, Lee BE, Kim TG, Choi JU, Kim DS, et al. Association of the miR$146 \mathrm{aC}>\mathrm{G}$, miR-196a2C $>$ T, and miR-499A $>\mathrm{G}$ polymorphisms with moyamoya disease in the Korean population. Neurosci Lett. 2012;521(1):71-5.

22. Wang F, Cao Y, Ma L, Pei H, Rausch WD, Li H. Dysfunction of cerebrovascular endothelial cells: prelude to vascular dementia. Front Aging Neurosci. 2018;10:376

23. Zhu X. Association of miRNAs and MTHFR gene polymorphisms with ischemic stroke in the Chinese Han population. Doctoral dissertation, Ph. D. Thesis. Qingdao: Qingdao University; 2016.

24. Zou D, Liu C, Zhang Q, Li X, Qin G, Huang Q, et al. Association between polymorphisms in microRNAs and ischemic stroke in an Asian population: evidence based on 6,083 cases and 7,248 controls. Clin Interv Aging. 2018; 13:1709.

25. Ncbi.nlm.nih.gov. (2019). rs 2292832 Ref SNP Report - db SNP - NCBI. [Online] Available at: http://www.ncbi.n/m.nih.gov/snp/rs2292832 [Accessed on 18 Aug.2019].

26. Du J, Cui C, Zhang S, Yang X, Lou J. Association of MicroRNA-146a and MicroRNA-149 polymorphisms with strokes in Asian populations: an updated meta-analysis. Angiology. 2017;68(10):863-70.

27. Xiao Y, Bao MH, Luo HQ, Xiang J, Li JM. A meta-analysis of the association between polymorphisms in microRNAs and risk of ischemic stroke. Genes. 2015:6(4):1283-99.

28. Choupani J, Nariman-Saleh-Fam Z, Saadatian Z, Ouladsahebmadarek E, Masotti A, Bastami M. Association of mir-196a-2 rs11614913 and mir-149 rs2292832 polymorphisms with risk of cancer: an updated meta-analysis. Front Genet. 2019;10:186.

29. Luo HC, Luo QS, Wang CF, Lei M, Li BL, Wei YS. Association of miR-146a, miR-149, miR-196a2, miR-499 gene polymorphisms with ischemic stroke in a Chinese people. Oncotarget. 2017:8(46):81295.

\section{Publisher's Note}

Springer Nature remains neutral with regard to jurisdictional claims in published maps and institutional affiliations. 